\title{
ContExtended Questions (CEQ) to Teach and Assess Clinical Reasoning: A New Variant of F-Type Testlets
}

\author{
Yavuz Selim Kıyak ${ }^{1 *}$, Işıl İrem Budakoğlu², Serdar Kula ${ }^{3}$ y Özlem Coşkun ${ }^{4}$ \\ Gazi University Faculty of Medicine, Ankara, Turkey; yskiyak@gazi.edu.tr, 0000-0002-5026-3234 \\ Gazi University Faculty of Medicine, Ankara, Turkey; isilirem@gazi.edu.tr, 0000-0003-1517-3169 \\ 3 Gazi University Faculty of Medicine, Ankara, Turkey; kula@gazi.edu.tr, 0000-0002-0728-1648 \\ 4 Gazi University Faculty of Medicine, Ankara, Turkey; drozlemcoskun@gmail.com, 0000-0001-8800-4433 \\ * Correspondence: yskiyak@gazi.edu.tr
}

Recibido: 10-02-2021; Aceptado: 21/02/2021; Publicado: 22/02/2021

\begin{abstract}
This study introduces ContExtended Questions (CEQ), which is a tool both to teach and assess clinical reasoning particularly in the preclinical years, and the web-based program to implement. CEQ consists of text-based case-based multiple-choice questions that provide patient data in a fixed and predetermined sequence. It enables the examinees to develop and reshape their illness scripts by using feedback after every question. Feedback operates to transform the examinee's failure into a "productive failure". The preliminary results of the randomized controlled experiment of teaching clinical reasoning to preclinical students through CEQ is quite satisfactory. In the medical education literature, this would be the first time that students, who have no or very limited clinical experience, developed their illness scripts just by taking formative multiple-choice tests. The approach would be named "test-only learning". The complete results of the experiment and then more experiments in other contexts and domains are necessary to establish a more powerful assessment tool and software. Furthermore, by changing the content of the questions, it is possible to use CEQ in every period of medical education and health professions education.
\end{abstract}

Keywords: clinical reasoning; case-based exam; multiple-choice; preclinical; productive failure

\section{Introduction}

Clinical reasoning is a cognitive process that is carried out by physicians during decision-making on the management of patients. It is an essential but not a generic skill that can be learned to apply in all clinical domains (1). According to script theory and illness scripts, learners develop the skill in a form of scripts as they gain experience about the clinical problems (2). In clinical years of undergraduate medical education, medical students could find an abundant number of opportunities to develop and reshape their illness scripts by dealing with patients in the clinical environments. Preclinical students, however, may not find enough opportunity to get ready for the clinical years, especially if the program is not well-integrated vertically. To teach clinical reasoning to undergraduate students in their first years, providing them "prototypal presentations of common diseases" is recommended (3). The most common way of teaching clinical reasoning for the preclinical years is case-based discussions (4). A well-established method with more than thirty years of implementation is Case- 
Based Clinical Reasoning Education (5) but it necessitates coaching in small groups that creates huge time cost to faculties (5). There is a need for a more efficient method that needs less human resources and time.

The aim of this paper is to present a novel electronic formative assessment tool to teach clinical reasoning to the students who have no or limited experience with real patients: ContExtended Questions (CEQ).

\section{The Structure of ContExtended Questions}

The structure of ContExtended Questions is as follows:

1. A brief (ill-defined/no more than two sentences) introduction to the clinical case: What is the main problem or symptom, and where is the problem or symptom being evaluated?

2. Stem of the question.

3. Correct options and distractors (correct + , distractor -, inert 0 point; sum of them is 0 point).

4. Examinees choose as many options as they want.

5. Feedback that consists of:

1. the points of the options,

2. the score of the examinee in the question,

3. open-ended, no more than two-paragraphs-long text that explains why the correct options are correct and the distractors are not.

6. The next part of the case.

7. Stem of the question.

8. Correct options and distractors (correct + , distractor -, inert 0 point; sum of them is 0 point).

9. Examinees choose as much options as they want.

10. Feedback that consists of:

1. the points of the options,

2. the score of the examinee in the question,

3. open-ended, no more than two-paragraphs-long text that explains why the correct options are correct and the distractors are not.

11. Repeat 6-10 as much as subject matter experts need.

12. Repeat 1-10 until the required number of cases are reached for the exam.

13. Provide standardized total score of the examinee as a feedback.

14. Provide all of the questions, options, answers, scores, and feedback to the examinee.

An example of the process from the examinee's perspective is provided in Figure 1. The first and last parts of a case, questions, and feedback of them from the examinee's perspective are provided in Figure 2 and Figure 3. Feedback that is located at the right-half of Figure 2 and Figure 3 consists of a) points of the options, b) the score of the examinee from the question, and c) open-ended feedback, from top to bottom. Figure 4 shows the logo of CEQ. 


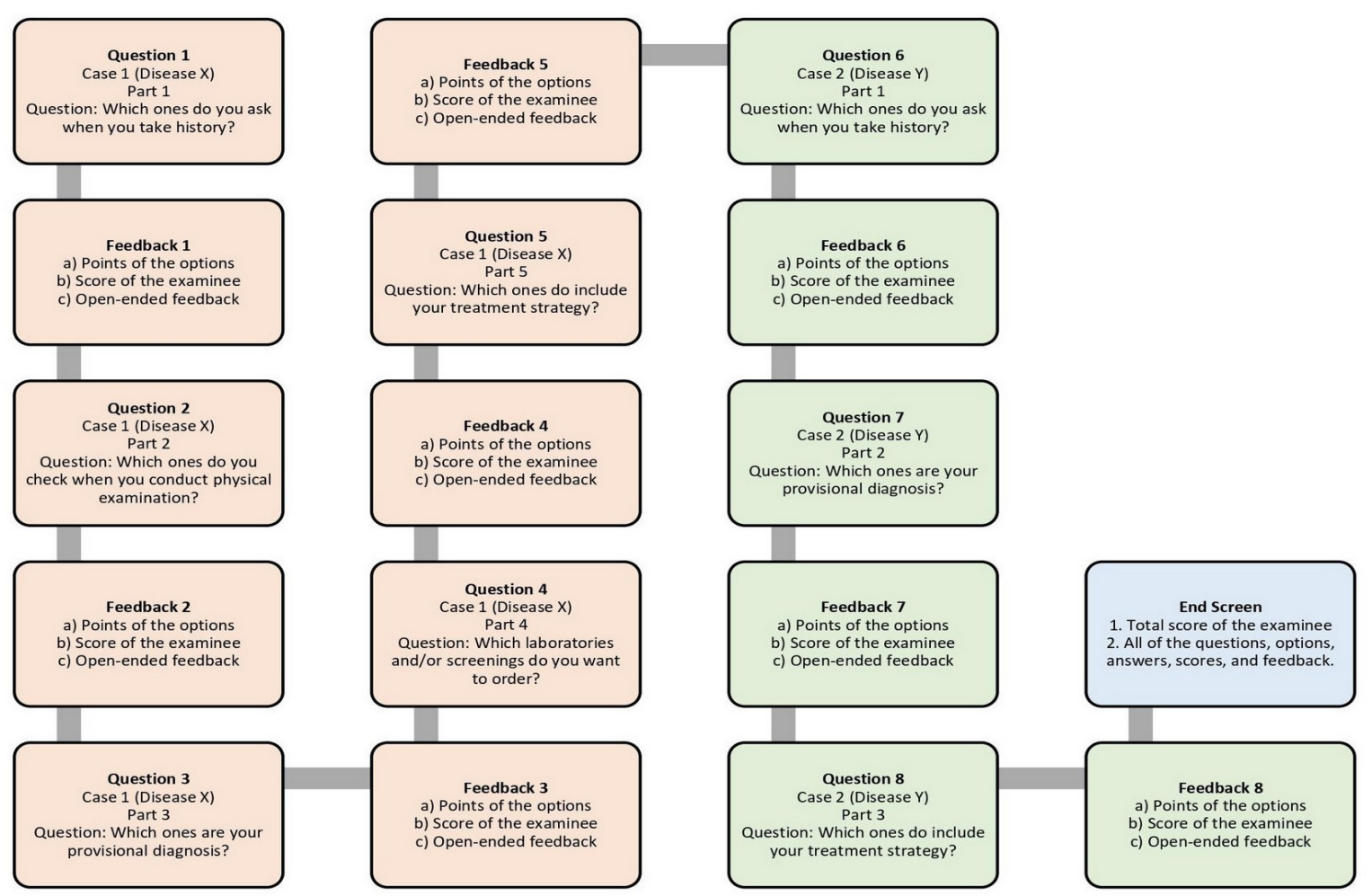

Figure 1. The path of every examinee consists of 8 questions nested in 2 cases

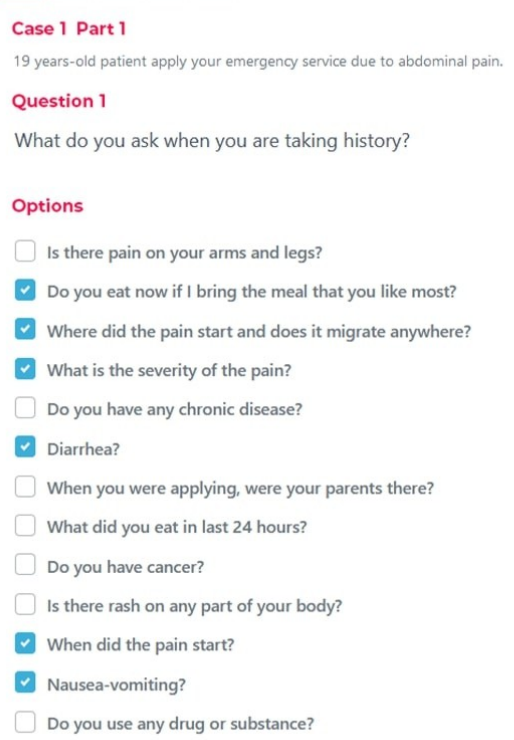

Case 1 Part 1

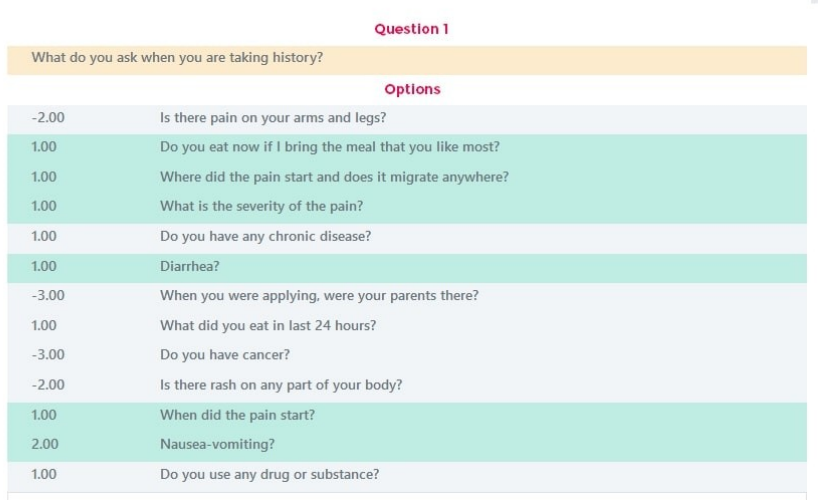

Your score in this question,

Starting time, migration, and severity of the pain should be asked since they give us important information. Nausea-vomiting is very important in patients who have abdominal pain. Loss of appetite (Do you eat now iff bring the meal that you like moste) is another important thing to ask these patients. Cancer should not be one of the first questions for young patients with abdominal pain. Rash and arm-leg pain are relatively irrelevant as wel. If a patient is above 18 , there is no need for parents to apply to a healthcare institution in our country.

Figure 2. The first part of a case, first question, and its feedback screen. 

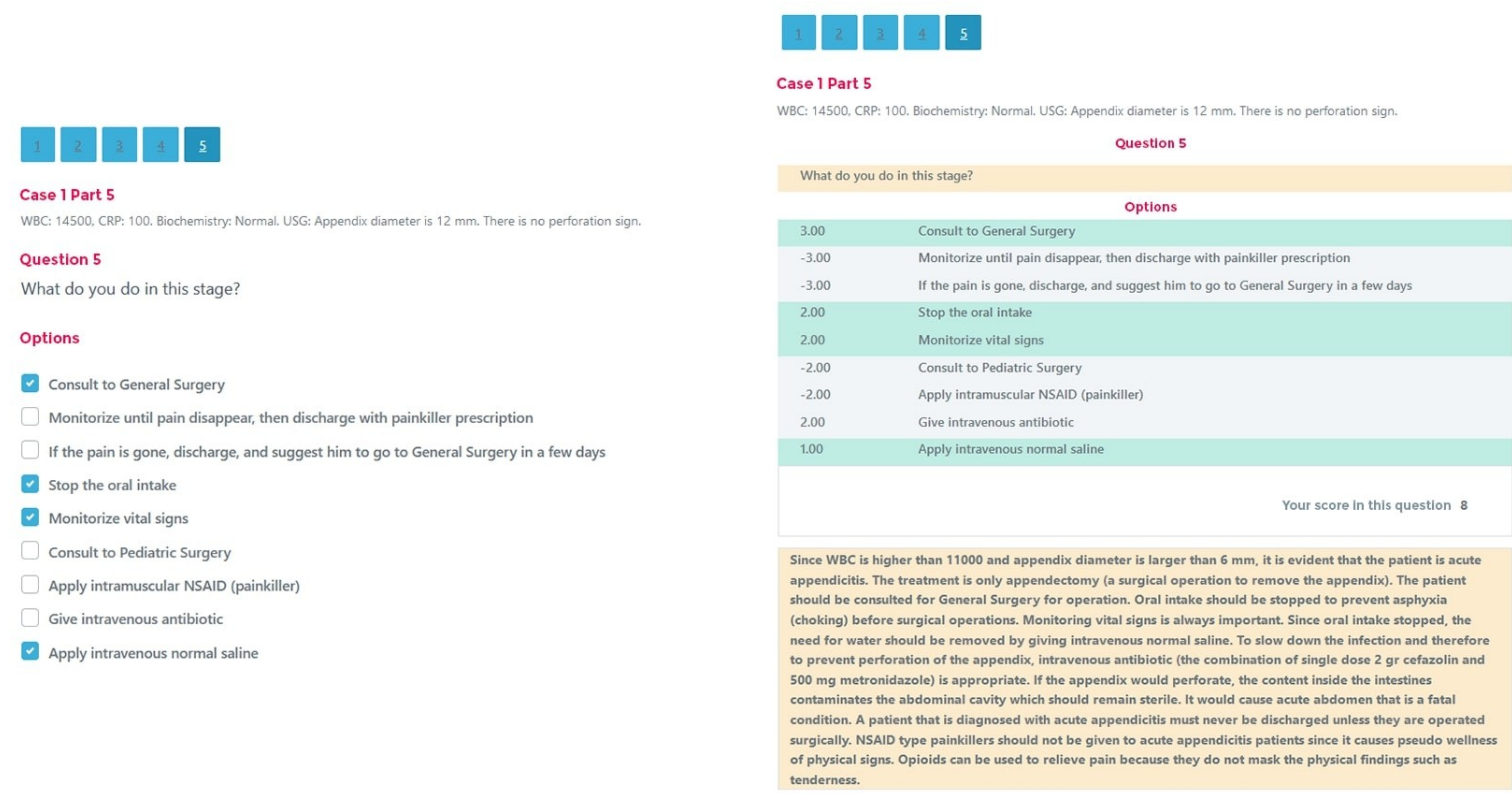

Figure 3. The last part of a case, last question, and its feedback screen.

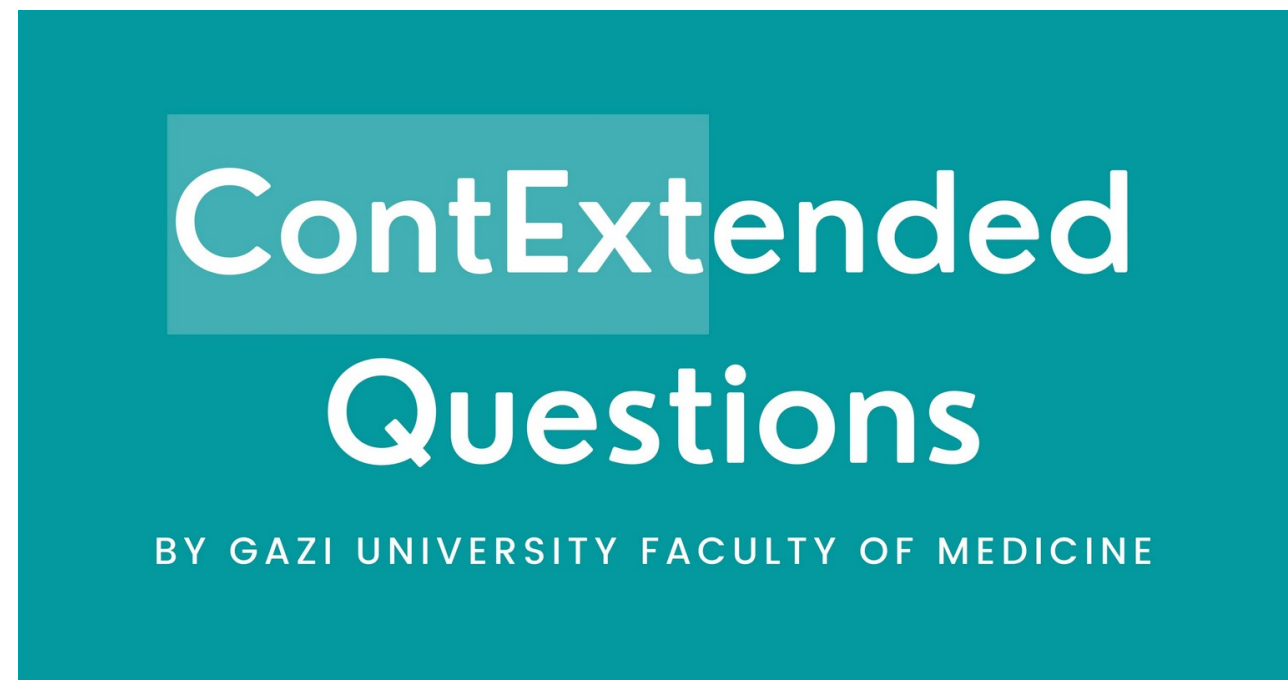

Figure 4. The logo of the ContExtended Questions.

\section{Method (The Theory Behind and the Roots of ContExtended Questions)}

ContExtended Questions (CEQ) is developed to teach and assess clinical reasoning. It is developed based on a) script theory (6), b) illness scripts (2), and c) F-type testlets (7-8). The inspiration to embarking on developing ContExtended Questions has come from the case-based exam that was put forward by Durak et al. (9) that do not use any electronic system to carry out this exam (9).

According to script theory, as the clinical experience related to a disease increases, the illness script of the disease should be more robust (2). The evidence 
shows that medical experts have no advanced memory but they have wellorganized illness scripts that are a result of clinical experiences (11). Practice with cases and corrective feedback is among the effective strategies to teach clinical reasoning (3). CEQ is designed to allow students to gain clinical experience by solving the text-based simulated cases repeatedly through testlets so that they develop their illness scripts.

Multiple-choice questions that are linked to each other and nested in cases are called "context-dependent item" or "testlet" (12). CEQ could be considered as a hybrid of patient management problems and extended matching questions. It could be seen as a version of F-type testlets (8). There is strong evidence that shows context-dependent questions are prone to assess higher levels of cognitive skills such as clinical reasoning (13). Therefore, CEQ is designed to be able to include the whole process related to patient management (history, physical examination, laboratory and screening, diagnosis, treatment, follow-up) to reflect the whole context as much as possible. Since context has high importance in the tool and its options similar to extended matching questions, the assessment tool we developed is named "ContExtended Questions".

CEQ is composed of multiple-choice questions instead of open-ended questions since multiple-choice questions a) allow us to carry out more objective assessment (14), b) enable us to reach higher levels of reliability (14), and c) are useful to assess higher levels of the cognitive domain (13).

CEQ gives feedback after every question not only to reinforce when they choose right options but also in order that feedback helps the examinee who fails to choose correct options. Feedback in CEQ is designed to operate as a remedy after failure in order to turn it into "productive failure" (15). An example of productive failure in health professions education is a randomized controlled experiment by Steenhof et al. (16). In the experiment, the pharmacy students were divided into two groups. The first group was provided a formula for calculating creatinine clearance. They were instructed on how to calculate by using this formula. The formula was not provided to the second group. They were asked to invent a formula to calculate creatinine clearance but they could not invent despite the fact that they strive for doing so. In the second phase of the experiment, the formula was provided to both of the groups and all of them were assigned to calculate creatinine clearance in some cases. This was the first time that the second group saw the formula. Both of the groups implemented the formula on the cases. In the delayed assessment, the second group outperformed the first group. It is concluded that the difference stems from the second group's first effort to invent the formula (16).

The feedback that is given between every question in CEQ is designed to match up with the recommendations from literature on how to give effective feedback, such as feedback should a) be given immediate and regularly, b) allow students to evaluate themselves, c) be specific, and d) be given in a way that does not contain any threatening language (17). Apart from those, it is well-known that multiple-choice questions without feedback could led to misinformation in the 
students (18). Also, evidence showed that open-ended feedback is more effective than revealing only true and false options of the questions (19). Text-based feedback in CEQ meets all of these recommendations and reduces the negative effects of multiple-choice questions.

Reflection on action is important to occur in self-regulated learning (20). Feedback should be given in a form that allows the learner to reflect on the learning process (17). By providing all questions, answers, and text-based feedback at the end of the session, CEQ allows examinees to reflect on the process.

A study showed that when every case is unfolded gradually (serial-cue), the students perform $72 \%$ worse than when every case is provided in a whole-case format (21). There was a similar result in another study (22). The reason behind the low performance in serial-cue approach is concluded as the high amount of cognitive load created by the difficulty of constructing a meaningful whole (23). Both studies, however, were carried out without feedback. We chose the serial-cue approach since CEQ allows examinees to turn their failure in every question into productive failure (16) by using feedback. Schmidt and Mamede (23) criticize serial-cue approach since it is a burden for educators providing feedback but CEQ gives feedback automatically in an electronic environment. Creating text-based feedback for every question only once is a relatively small burden compared to personalized feedback. Serial-cue approach enables CEQ to have high face validity as well.

Since the medical information can not be processed without the environment where it would be used (24), CEQ requires test designers to indicate the place where the case is being dealt with such as emergency room, primary care clinic, street, etc. It also strengthens the authenticity. Another element that enhances the authenticity of CEQ is the options that could be positive, negative, or zero points. Its structure matches up with the consequences of the decisions made by health professionals.

Despite the strengths of the CEQ, it has limitations as well. The first limitation is that it requires either a computer, tablet, or smartphone with an internet connection which is a problem for the students who live in underdeveloped regions. The other limitation is that even if it does not require hours of discussions, developing CEQ cases, questions, and feedback is still a burden for the faculty. However, when a CEQ is developed once, it could be used over and over.

\section{Preliminary Results on the Effect of CEQ}

We conducted a randomized controlled experiment with preclinical (third year of six-year-long undergraduate education) medical students between November 20, 2020 and December 8, 2020. The intervention was a CEQ exam of general surgery questions. The intervention group has completed CEQ every day for 18 days. The control group has taken placebo (questions not related to general surgery). All of the participants took the same pre-test and post-test that consists of Key Feature Questions from the general surgery domain. Preliminary results 
showed that the post-test scores of the intervention group were significantly better than both their pre-test scores and the control group's post-test scores $(p<0.05)$.

The entire analysis will be reported in the future but in medical education literature, this is the first time that preclinical students developed their clinical reasoning skills just by taking multiple-choice tests. The method in a broad sense may be called "test-only learning" instead of test-enhanced learning since CEQ does not contain any teaching activity other than testing.

\section{Conclusion}

- ContExtended Questions is a novel tool to both teach and assess clinical reasoning skills, especially in preclinical years or the beginning of the clinical years. It allows the examinees to develop and reshape their illness scripts by using feedback after every question. Feedback operates to turn their failure into a "productive failure", and to reinforce right choices that they make in the test.

- The preliminary results of teaching clinical reasoning through CEQ is quite satisfying in preclinical students. In the medical education literature, this would be the first time that preclinical students developed their illness scripts just by taking formative multiple-choice tests. This approach may be named "test-only learning".

- The full results of the current experiment and then more experiments in different contexts and domains are needed to establish more robust method and software. Furthermore, by changing content of the questions, CEQ could be used to teach and assess clinical year medical students, medical residents, doctors, or the other health professions students. It could open a new door into the use of CEQ in every period of medical education and health professions education.

Financial Support: This study was conducted to contribute to the PhD Thesis of Yavuz Selim Kiyak, "Developing A New Method and Electronic System for Assessment of Clinical Reasoning Skills in Medical Education". Gazi University Projects of Scientific Investigation (BAP) supported the study (code: 01/2020-24).

Acknowledgement: We would like to thank to Okan Kullep for his valuable technical support.

Declaration of Conflict of Interest: There is no conflict of interest.

\section{References}

1. Norman G. Research in clinical reasoning: past history and current trends. Med Educ, 2005, 39(4), 418-427. DOI: 10.1111/j.1365-2929.2005.02127.x https://onlinelibrary.wiley.com/doi/full/10.1111/j.1365-2929.2005.02127.x

2. Custers EJ. Thirty years of illness scripts: Theoretical origins and practical applications. Med Teach, 2015, 37(5), 457-462. DOI: 10.3109/0142159X.2014.956052 https://www.tandfonline.com/ doi/full/10.3109/0142159X.2014.956052

3. Cooper N, Da Silva AL, Powell S. Teaching clinical reasoning. En ABC of Clinical Reasoning; 1. ed.; Cooper N, Frain J, Eds.; Editorial: Chichester, UK, 2016, 44-50.

4. Kassirer JP. Teaching clinical reasoning: case-based and coached. Acad Med 2010, 85(7), 1118$1124 . \quad$ DOI: 10.1097/ACM.0b013e3181d5dd0d https://journals.lww.com/academicmedicine/Fulltext/2010/07000/Teaching Clinical Reasoni ng Case Based and.11.aspx

5. Ten Cate O, Custers EJ, Durning SJ, Eds. Principles and Practice of Case-based Clinical Reasoning Education: A Method for Preclinical Students. Springer, 2018. https://www.springer.com/gp/book/9783319648279

6. Schank RC, Abelson RP. Scripts, plans, and knowledge. IJCAI 1975, 75, 151-157. https://home.mis.u-picardie.fr/ furst/docs/Schank Abelson Scripts 1975.pdf 
7. Wainer H, Bradlow ET, Wang X. Testlet response theory and its applications. Cambridge, UK, 2007.

8. Jolly B, Dalton MJ. Written Assessment. En Understanding medical education: evidence, theory and practice; Swanwick T, Forrest K, O’Brien BC, Eds.; New Jersey, USA, 2019, 291-317.

9. Durak HI, Caliskan SA, Bor S, Van Der Vleuten C. Use of case-based exams as an instructional teaching tool to teach clinical reasoning. Med Teach, 2007, 29(6), e170-e174. DOI: 10.1080/01421590701506866

https://www.tandfonline.com/doi/full/10.1080/01421590701506866

10. Lubarsky S, Dory V, Audétat MC, Custers E, Charlin B. Using script theory to cultivate illness script formation and clinical reasoning in health professions education. Can Med Educ J, 2015, 6(2), e61. https://www.ncbi.nlm.nih.gov/pmc/articles/PMC4795084/

11. Cooper N, Bartlett M, Gay S, Hammond A, Lillicrap M, Matthan J, Singh M. UK Clinical Reasoning in Medical Education (CReME) consensus statement group. Consensus statement on the content of clinical reasoning curricula in undergraduate medical education. Med Teach, 2020, 1-8. $\quad$ DOI: https://www.tandfonline.com/doi/full/10.1080/0142159X.2020.1842343

12. Haladayna TM, Downing SM, Rodriguez MC. A review of multiple-choice item-writing guidelines for classroom assessment. Appl Meas Educ, 2002, 15(3), 309-333. DOI: 10.1207/S15324818AME1503_5 https://www.tandfonline.com/doi/abs/10.1207/S15324818AME1503_5

13. Pugh D, De Champlain A, Touchie C. Plus ça change, plus c'est pareil: making a continued case for the use of MCQs in medical education. Med Teach, 2019, 41(5), 569-577. DOI: 10.1080/0142159X.2018.1505035 https://www.tandfonline.com/doi/full/10.1080/0142159X.2018.1505035

14. Shumway JM, Harden RM. AMEE Guide No. 25: The assessment of learning outcomes for the competent and reflective physician. Med Teach, 2003, 25(6), 569-584. DOI: 10.1080/0142159032000151907 https://www.tandfonline.com/doi/abs/10.1080/0142159032000151907

15. Kapur M. Productive failure. Cogn Instr, 2008, 26(3), 379-424. DOI: 10.1080/07370000802212669 https://www.tandfonline.com/doi/full/10.1080/07370000802212669

16. Steenhof N, Woods NN, Van Gerven PW, Mylopoulos M. Productive failure as an instructional approach to promote future learning. Adv Health Sci Educ, 2019, 24(4), 739-749. DOI: 10.1007/s10459-019-09895-4 https:/ / link.springer.com/article/10.1007/s10459-019-09895-4

17. Ramani S, Krackov SK. Twelve tips for giving feedback effectively in the clinical environment. Med Teach, 2012, 34(10), 787-791. DOI: 10.3109/0142159X.2012.684916 https://www.tandfonline.com/doi/full/10.3109/0142159X.2012.684916

18. Butler AC, Roediger HL. Feedback enhances the positive effects and reduces the negative effects of multiple-choice testing. Mem Cognit, 2008, 36(3), 604-616. DOI: 10.3758/MC.36.3.604 https://link.springer.com/article/10.3758/MC.36.3.604

19. Black P, Wiliam D. Assessment and classroom learning. Assessment in education: principles. Policy Pract, 2006, 5(1), 7-74. DOI: 10.1080/0969595980050102 https://www.tandfonline.com/doi/abs/10.1080/0969595980050102

20. Sandars J. The use of reflection in medical education: AMEE Guide No. 44. Med Teach, 2009, 31(8), 685-695. DOI: $\quad$ 10.1080/01421590903050374 https://www.tandfonline.com/doi/full/10.1080/01421590903050374

21. Nendaz MR, Raetzo MA, Junod AF, Vu NV. Teaching diagnostic skills: clinical vignettes or chief complaints?. Adv Health Sci Educ, 2000, 5(1), 3-10. DOI: 10.1023/A:1009887330078 https://link.springer.com/article/10.1023/A:1009887330078

22. Pinnock R, Anakin M, Lawrence J, Chignell H, Wilkinson T. Identifying developmental features in students' clinical reasoning to inform teaching. Med Teach, 2019, 41(3), 297-302. DOI: 10.1080/0142159X.2018.1463433

https://www.tandfonline.com/doi/full/10.1080/0142159X.2018.1463433 
23. Schmidt HG, Mamede S. How to improve the teaching of clinical reasoning: a narrative review and a proposal. Med Educ, 2015, 49(10), 961-973. DOI: 10.1111/medu.12775 https://onlinelibrary.wiley.com/doi/full/10.1111/medu.12775

24. Durning SJ, Artino AR. Situativity theory: a perspective on how participants and the environment can interact: AMEE Guide no. 52. Med Teach, 2011, 33(3), 188-199. DOI: 10.3109/0142159X.2011.550965

https://www.tandfonline.com/doi/full/10.3109/0142159X.2011.550965

(C) 2021 by the authors. Submitted for open access publication under license terms and conditions Creative Commons Attribution (CC BY)

(http://creativecommons.org/licenses/by/4.0/). 